\title{
BINOCULAR PERFORMANCE IN PATIENTS WITH UNILATERAL CATARACT USING THE REGAN TEST: BINOCULAR SUMMATION AND INHIBITION WITH LOW- CONTRAST CHARTS
}

\author{
S. PARDHAN \\ Bradford
}

\begin{abstract}
SUMMARY
Recent reports have shown that binocular contrast sensitivity is an important indicator for assessing the visual function of a unilateral cataract. Binocular sensitivity, assessed in terms of binocular summation and inhibition, is dependent on the difference between the two eyes. Maximum binocular summation, obtained when the sensitivities of two eyes are equal, decreases if they are made unequal. Further increases in the monocular difference produce binocular inhibition, defined as a binocular sensitivity which is lower than the monocular. The aim of this study was to investigate whether the binocular effects in unilateral cataract that have been shown using laboratory-based equipment can be demonstrated using commercially available Regan charts. Binocular scores were compared with monocular scores in 16 unilateral cataract patients and 16 aged-matched normals using a highcontrast chart $(96 \%)$ and a low-contrast $(11 \%)$ chart. Normal subjects showed binocular summation with both charts. The cataractous patients showed no summation at high contrast and binocular inhibition with low-contrast charts. The implications of binocular inhibition at low contrast are discussed.
\end{abstract}

Contrast sensitivity measurement is considered important in the detection and monitoring of ocular impairment. ${ }^{1-6}$ Binocular contrast sensitivity, in particular, has been advocated as a valuable indicator in assessing the visual disability of a cataractous patient. ${ }^{7}$ It is well known that when the sensitivities of the two eyes are equal, the binocular performance is superior to that of monocular. This is called binocular summation, evidence of which has been observed in a variety of tasks including visual acuity, contrast sensitivity and measurements of visual evoked

Correspondence to: Dr Shahina Pardhan, Clinical Vision Research Group, Department of Optometry, University of Bradford, West Yorkshire BD7 1DP, UK. response. ${ }^{8.9}$ Binocular summation is less evident when the two eyes are not equal. Fechner, as early as 1860 , observed that when a neutral density filter is placed in front of one eye, the binocular perception of brightness is lower compared with that obtained when the eye behind the filter is closed. ${ }^{10}$ This lowering of binocular sensitivity to a level below the sensitivity of the good eye has been termed binocular inhibition. ${ }^{11.12}$ Laboratory investigation has demonstrated binocular inhibition in different conditions including induced monocular defocus ${ }^{13}$ and monocular glare disability. ${ }^{14}$ If the impediment producing the difference in the two eyes is removed, the binocular performance reverts to the summation level.

Binocular inhibition has been observed clinically in unilateral cataractous patients, who report an improvement in vision on closing their cataractous eye. ${ }^{15}$ This was shown in the laboratory using computerised equipment that is expensive, cumbersome and inefficient. Since then, other studies have reported binocular inhibition in unilateral cataractous patients using practitioner-friendly contrast sensitivity charts including the Cambridge ${ }^{16}$ and Pelli Robson ${ }^{17}$ tests. Taylor et al. ${ }^{16}$ claimed that some patients demonstrated binocular inhibition with high-contrast acuity test while others showed it with contrast sensitivity. Since it is difficult to compare results of these two tests directly, they suggested that both visual acuity measurement and contrast sensitivity be employed in assessing the visual function of a unilateral cataract. Contrast sensitivity measurement gives an indication of the patient's ability to detect low-contrast targets whilst visual acuity gives a measure of the resolution at high contrast. A direct comparison between these two measures is impossible. One of the main difficulties in comparing results from different tests is the incompatibility of their designs and scoring systems. A test that measures the visual performance at high and low contrast levels with the same 
scoring units would allow such a comparison. The Regan test consists of various charts that measure visual performance at different contrast levels. The aim of this study was to investigate whether the Regan test is able to assess the binocular visual function in terms of summation and inhibition in unilateral cataractous patients. Regan charts have been shown to be useful in the diagnosis of multiple sclerosis, ${ }^{18-20}$ optic neuropathies, ${ }^{21}$ macular degeneration, ${ }^{22}$ paediatric dysfunction, ${ }^{23,24}$ diabetes, ${ }^{25}$ ocular hypertension, ${ }^{26}$ glaucoma, ${ }^{27,28}$ and ageing. ${ }^{29}$

\section{METHOD}

\section{Regan Chart}

The Regan charts are not, strictly speaking, a test of contrast sensitivity, which is defined as the amount of contrast required to detect a target. The charts measure visual acuity at different contrast levels. The test comprises several charts of different contrasts, with the contrast remaining constant for each chart. The available contrast levels include $96 \%, 50 \%, 25 \%, 11 \%$ and $4 \%$. Each chart contains 11 rows of letters, the score for the top row being 1 and for the bottom 11. Each row comprises of eight letters with the letter sizes decreasing by a ratio of 1.26:1. A drop of one line, therefore, corresponds to the same fractional loss of visual acuity, independent of the initial visual acuity.

For scoring, each letter in a row is allocated a score of 0.125 , with eight letters giving a total score of 1 per row. A subject who, for example, reads five letters correctly after row 4, would be given a score of 5.625.

\section{Patients}

Sixteen normal subjects (aged $62.5+5.5$ years) were recruited from the undergraduate optometry clinic, University of Bradford. A full optometric examination was given to each subject and they were included only if they had no history of amblyopia or squint, no ocular abnormality seen by direct ophthalmoscopy, a refractive error of less than $\pm 6.00 \mathrm{DS}$ or $\pm 2.50 \mathrm{DC}$ and anisometropia less than 1.00 DS. All subjects had monocular Snellen acuity of at least $6 / 6$ right and left.

Sixteen unilateral cataract patients took part in this study. All patients had normal neural function as determined by direct ophthalmoscopy, retinal interferometry and displacement threshold acuity. The Snellen acuity of the non-cataractous eye was at least $6 / 6$ and that of the cataractous eye ranged between 6/9 and 6/18.

Binocular and monocular scores were obtained with the $96 \%$ and $11 \%$ contrast charts at 10 feet $(3 \mathrm{~m})$, as recommended in the manual. To avoid familiarisation with the letters on the charts, both versions of the charts were used. All measurements were taken using normal pupils.

Table I. Normal subjects

\begin{tabular}{lll}
\hline Contrast & $\begin{array}{l}\text { Monocular } \\
\text { difference }\end{array}$ & $\begin{array}{l}\text { Binocular } \\
\text { ratio }\end{array}$ \\
\hline High $(96 \%)$ & $0.26 \pm 0.11$ & $1.32 \pm 0.12$ \\
Low $(11 \%)$ & $0.29 \pm 0.07$ & $1.31 \pm 0.14$ \\
\hline
\end{tabular}

\section{RESULTS}

The results for the normal subjects are shown in Table I. The differences in the monocular scores are obtained by subtracting the score of the worst eye from that of the good eye. The binocular ratio is computed as a ratio of the binocular score over the score of the good eye. A binocular ratio greater than 1 indicates binocular summation whilst a ratio of less than 1 denotes binocular inhibition. Table II shows the scores for the cataractous patients. The monocular difference score is obtained by subtracting the cataractous score from the non-cataractous score.

The normal group showed binocular summation ratios of $32 \%$ and $31 \%$ with high-contrast and low-contrast charts respectively. The monocular differences were similar at both contrast levels. The cataractous group, on the other hand, showed a greater monocular difference with the low-contrast chart compared with the high-contrast chart. The binocular score is also different for the two charts. At high contrast, the group shows no difference between the binocular and monocular sensitivities. At low-contrast level, however, binocular inhibition is produced.

For the normal group, the Wilcoxon test showed a significant difference between the binocular score and the monocular score with both high-contrast scores $(n=16$, $p=0.0006)$ and low-contrast scores $(n=16, p=0.0006)$. For the cataractous group, there was no significant difference between the binocular scores and non-cataractous scores at the high-contrast level $(n=16, p=0.61)$. The $11 \%$ contrast scores, on the other hand, showed a significant difference between the binocular and monocular scores $(n=16$, $p=0.0013$ ).

\section{DISCUSSION}

The monocular data on the unilateral cataractous patients show a greater visual disability at low contrast levels compared with high contrast. The normative group, on the other hand, shows similar monocular differences at both high and low contrast levels, in agreement with previous studies. $^{27}$ This has important clinical implications. Patients who demonstrate only subtle monocular differences with high-contrast Snellen chart may show a more substantial visual disability at low-contrast conditions.

This study shows that the binocular impairment in unilateral cataracts, shown previously using laboratory-based equipment, can be demonstrated using the Regan test. In high-contrast conditions, cataractous patients show equal binocular and monocular sensitivities. In low-contrast conditions, however, the binocular sensitivity is lower than that of non-cataractous eye, showing binocular inhibition. Previous studies claim that the degree of binocular sensitivity depends on the difference between the two

Table II. Cataractous patients

\begin{tabular}{lll}
\hline Contrast & $\begin{array}{l}\text { Monocular } \\
\text { difference }\end{array}$ & $\begin{array}{l}\text { Binocular } \\
\text { ratio }\end{array}$ \\
\hline High $(96 \%)$ & $1.48 \pm 0.13$ & $0.99 \pm 0.17$ \\
Low $(11 \%)$ & $2.53 \pm 0.26$ & $0.86 \pm 0.08$ \\
\hline
\end{tabular}


eyes. ${ }^{14-16}$ Equal monocular sensitivities produce binocular summation, which decreases to binocular inhibition as the difference between the two eyes increases. Following this, it is likely that in high-contrast conditions the monocular difference in this particular group of patients produces a lowering of binocular sensitivity to match the monocular. Further increasing the monocular difference in low-contrast conditions results in binocular inhibition.

The measurement of high-contrast acuity is an established part of a routine visual examination. The importance of low-contrast letter charts as a measure of contrast sensitivity has been debated recently. ${ }^{30-32}$ One main advantage of using low-contrast charts is that they are more representative of a visual environment in low-contrast conditions (e.g. road signs in foggy weather). It is important that these binocular measurements are obtained in unilateral cataractous patients even when the acuity in the fellow eye is high. If ophthalmological decisions were made on high-contrast monocular measurement only, important information about the patient's visual function in different environmental conditions would be overlooked. This could be especially important for those patients who work in low-contrast conditions or in glare. It is well known that cataract increases glare disability. ${ }^{33}$ The existence of binocular inhibition in glare has been reported. ${ }^{13}$ Patients who show no binocular impairment in normal conditions may do so in bright sunlight as their visual disability increases. Patients who complain of better monocular vision than binocular vision should be tested in different conditions to establish the true extent of their complaint.

It has been shown recently that symptoms decrease in unilateral pseudoaphakic patients when the fellow cataract is extracted..$^{34}$ In an age in which the frequency of cataract extraction is increasing, ${ }^{35-37}$ decisions have to be made as to who should be given priority for extraction. Binocular inhibition could be used as an additional criterion to help make that decision, patients who show binocular inhibition being given priority over those who do not.

I would like to thank Mr. Jim Gilchrist for the helpful discussions on the subject and Dr. Janet Hesler for providing the patients and base data on them. I would also like to thank Mr. A. Shakespeare for help with technical details.

Key words: Binocular inhibition, Binocular summation, Low-contrast charts, Unilateral cataract.

\section{REFERENCES}

1. Hess R, Woo G. Vision through cataracts. Invest Ophthalmol Vis Sci 1978;17:426-35.

2. Elliott DB, Gilchrist J, Whitaker D. Contrast sensitivity and glare sensitivity changes with three types of cataract morphology: are these techniques necessary in a clinical evaluation of cataract? Ophthalmic Physiol Opt 1989;9:25-30.

3. Harbin TS. Visual impairment by sunlight in posterior subcapsular cataract. Ophthalmic Surg 1973;4:34-6.

4. Skalka HW. Arden grating test in evaluating early posterior subcapsular cataracts. South Med J 1981;74:1368-70.

5. Elliott DB, Gilchrist J, Hurst M, Pickwell LD, Sheridan M, Weatherill J, Whitaker D. The subject assessment of cataract. Ophthalmic Physiol Opt 1989;9:16-9.
6. Brown N. The morphology of cataract and visual performance. Paper presented at Oxford Ophthalmological Congress, 1992.

7. Elliott D, Hurst M, Weatherill J. Comparison tests of visual function in cataract with patient's perceived visual disability. Eye 1990;4:712-7.

8. Blake R, Fox R. The psychophysical inquiry into binocular summation. Percept Psychophysics 1973;14:161-85.

9. Blake R, Sloane M, Fox R. Further developments in binocular summation. Percept Psychophysics 1981;30:266-76.

10. Fechner G. Elemente der Psychophysik. Leipzig: Breitkopf and Hartlet.

11. Gilchrist J, McIver C. Fechner's paradox in binocular contrast sensitivity. Vis Res 1985;25:609-13.

12. Pardhan S, Gilchrist J, Douthwaite W. The effect of spatial frequency on binocular contrast inhibition. Ophthalmic Physiol Opt 1989;9:46-9.

13. Pardhan S, Gilchrist J. Binocular contrast sensitivity with monocular glare disability. Ophthalmic Physiol Opt 1990; 10:37-9.

14. Gilchrist J, Pardhan S. The effect of monocular defocus on binocular contrast sensitivity. Ophthalmic Physiol Opt 1990;10:33-6.

15. Pardhan S, Gilchrist J. The importance of measuring binocular contrast sensitivity in unilateral cataract. Eye 1990;5: 31-5.

16. Taylor RH, Misson GP, Moseley MJ. Visual acuity and contrast sensitivity in cataract: summation and inhibition of visual performance. Eye 1991;5:704-7.

17. Pardhan S, Elliott D. Clinical measurements of binocular summation and inhibition in patients with cataract. Clin Vis Sci 1991;6:355-9.

18. Regan D, Maxner C. Orientation-dependent loss of contrast sensitivity for pattern and flicker in multiple sclerosis. Clin Vis Sci 1986;1:1-23.

19. Regan D, Neima D. Low-contrast letter charts as a test of the visual function. Ophthalmology 1983;90:1192-200.

20. Poser CM. The diagnosis of multiple sclerosis. New York: Thieme-Stratton, 1984.

21. Druker MD, Savino PJ, Sergott RC, Bosley TM, Schatz NJ, Kubilis PS. Low-contrast letter charts to detect subtle neuropathies. Am J Ophthalmol 1988;105:141-5.

22. Kleiner RC, Auer C, Alexander M, Fine SL. Contrast sensitivity in age related macular degeneration. Invest Ophthalmol Vis Sci Suppl. 1986;27:21.

23. Regan D. Low-contrast acuity test for paediatric use. Can Vis Sci 1988;23:224-7.

24. Kothe A, Regan D. Crowding depends on contrast. Optom Vis Sci 1990;67:283-6.

25. Regan D, Neima D. Low-contrast letter charts in early diabetic retinopathy, ocular hypertension, glaucoma and Parkinson's disease. Br J Ophthalmol 1984;68:885-9.

26. Moskowitz A, Sokol S, Bardenstein D, Schwartz B. Performance of ocular hypertension and glaucoma patients on high and low-contrast letter charts. Invest Ophthalmol Vis Sci Suppl. 1986;27:225.

27. Regan D. Low-contrast charts and sinewave gratings in ophthalmological and neurological disorders. Clin Vis Sci 1988;2:235-50.

28. Lempert P, Hopcroft M, Lempert Y. Evaluation of posterior subcapsular cataracts. Ophthalmology (Instrument and Book Suppl) 1987:14-18.

29. Owsley C, Sloane M, Skalka HW, Jackson CA. A comparison of the Regan low-contrast letter charts and contrast sensitivity testing in older patients. Clin Vis Sci 1990;5:325-34.

30. Leguire LE. Do letter charts measure contrast sensitivity? Clin Vis Sci 1991;6:391-400.

31. Regan D. Do letter charts measure contrast sensitivity? Clin Vis Sci 1991;6:401-8.

32. Pelli DG, Robson JG. Are letters better than gratings? Clin Vis Sci 1991;6:409-11. 
33. Strong N. The effect of glare upon visual performance. Paper presented at Oxford Ophthalmological Congress 1992.

34. Laidlaw A, Harrad R. Symptomatic and functional benefits from the second eye cataract extraction. Can surgery be justified? Paper presented at Oxford Ophthalmological Congress, 1992.

35. Batternbury M, Khaw PT, Hands R, Elkington AR. The cat- aract explosion: the changing pattern of diagnoses of patients attending an ophthalmic outpatients department. Eye 1991;5:369-72.

36. Drummond MF, Yates JM. Clearing the cataract backlog in a (not so) developing country. Eye 1991;5:481-6.

37. Jay JL, Devlin ML. The increasing frequency of surgery for cataract. Eye 1990;4:127-31. 